\title{
Cost-benefit analysis of different solutions for sustainable irrigation in Fucino Plain (Italy)
}

\author{
E. Frank ${ }^{1}$, A. Gallina ${ }^{2}$, M. Baldacci ${ }^{2} \&$ M. Miolo ${ }^{1}$ \\ ${ }^{1}$ BETA Studio srl, Italy \\ ${ }^{2} H R$ Wallingford, UK
}

\begin{abstract}
The Fucino Plain $\left(200 \mathrm{~km}^{2}\right)$ was the largest lake in Central Italy prior to the 1800 s when it was reclaimed for agricultural use. In the past 15 years the original crops, mostly wheat, maize and sugar beet, have been progressively replaced with much more profitable (but more water demanding) horticultural crops. Increasing demand for water together with the actual irrigation techniques and the changes in the climate (decreasing precipitation and increasing temperatures) has caused a number of environmental and social-economical problems. These are mainly related to groundwater resource depletion, spring exhaustion, a decline in summer and annual surface water discharges, scarcity of irrigation water and conflict between different users. Based on a comprehensive study of water supply and demand, several measures for a sustainable use of water were considered. These were mainly related to the implementation of more efficient irrigation techniques, the increase of storage capacity and, subsequently, a reduction in the use of ground water. An accurate cost-benefit analysis showed a positive environmental impact (decline of $70 \%$ of ground water exploitation, reduction of energy consumption) and social benefits (increasing of quantity and quality of agricultural production) for the chosen solution.
\end{abstract}

Keywords: sustainable irrigation, irrigation systems and planning, cost-benefit analysis, water balance models, water resource management.

\section{Introduction}

In the recent past water availability in the Fucino Plain was not a problem: both agriculture and public water supply needs were met using surface water from canals and springs. Since the 1950s, the increasing water demand was satisfied 
by pumping groundwater from wells on the boundaries of the Plain where the limestone aquifers, considered as a virtually inexhaustible resource, are located. Over the past two decades the rising demand for water for agriculture and human uses (civic and industrial) has exceeded supply creating a negative supplydemand balance in dry years and during specific high demand periods in 'normal' years. This situation has caused various environmental and socioeconomic problems mainly related with groundwater resource depletion, spring exhaustion, a decline in surface water discharges, scarcity of irrigation water and conflict between different users (Burri and Petitta [1]).

A comprehensive study (BETA Studio and HR Wallingford [2]) financed by Liri-Garigliano and Volturno River Basin Authority and Abruzzo Region, was carried out to identify different solutions to the problem and to suggest the best solution from a technical, environmental and economic point of view.

The first part of the study completed a detailed analysis of all the different aspects connected to the water balance: climate, hydrology, hydrogeology, social and economics issues and infrastructure, making use of knowledge, experience and initiatives of the different stakeholders. The accurate knowledge of all those aspects made it possible to implement and validate a monthly water balance model of the study area. The analysis of the results of the water balance highlight all the different problems (present state and future) related to water availability and water uses in the basin, taking into account both quantity and quality issues. To solve these problems a number of measures (structural and non-structural) were proposed for all the different sectors analysed (civic and industrial water supply, water collection and treatment, irrigation). This paper considers the problem and the results obtained from an analysis of the irrigation sector. It shows that measures proposed are able to close the supply-demand balance and reduce environmental and social problems with a positive cost-benefit balance.

\section{Study area}

The study area is the Fucino basin $\left(900 \mathrm{~km}^{2}\right)$ located in the carbonate Apennine range in central Italy (Figure 1). In the centre of the basin is a $200 \mathrm{~km}^{2}$ alluvial plain that used to be the location of the largest lake of central Italy prior to the late 1800 s when a tunnel was made to drain the lake so that the area could be used as farmland. The drainage was completed in 1875 by Prince Torlonia and the necessary infrastructure was built including $210 \mathrm{~km}$ of roads, over $100 \mathrm{~km}$ of canals and $618 \mathrm{~km}$ of drainage ditches, in addition of farm-houses and stables (Brisse and De Rotrou [3]). The disappearance of the lake caused important social changes due to the transition of the local economy from fisheries to farming but also relevant environmental impacts caused by the disappearance of a balanced biological ecosystem.

The Fucino Plain is encircled by limestone ridges, bounded by extensional or thrust belt faults (Ciotoli et al [4]). Since Pliocene times, the endorheic depression has been filled by terrigenous, detrital and lacustrine alluvial deposits. The Plain is drained by artificial canals that collect water and direct it to the tunnel outflow. 


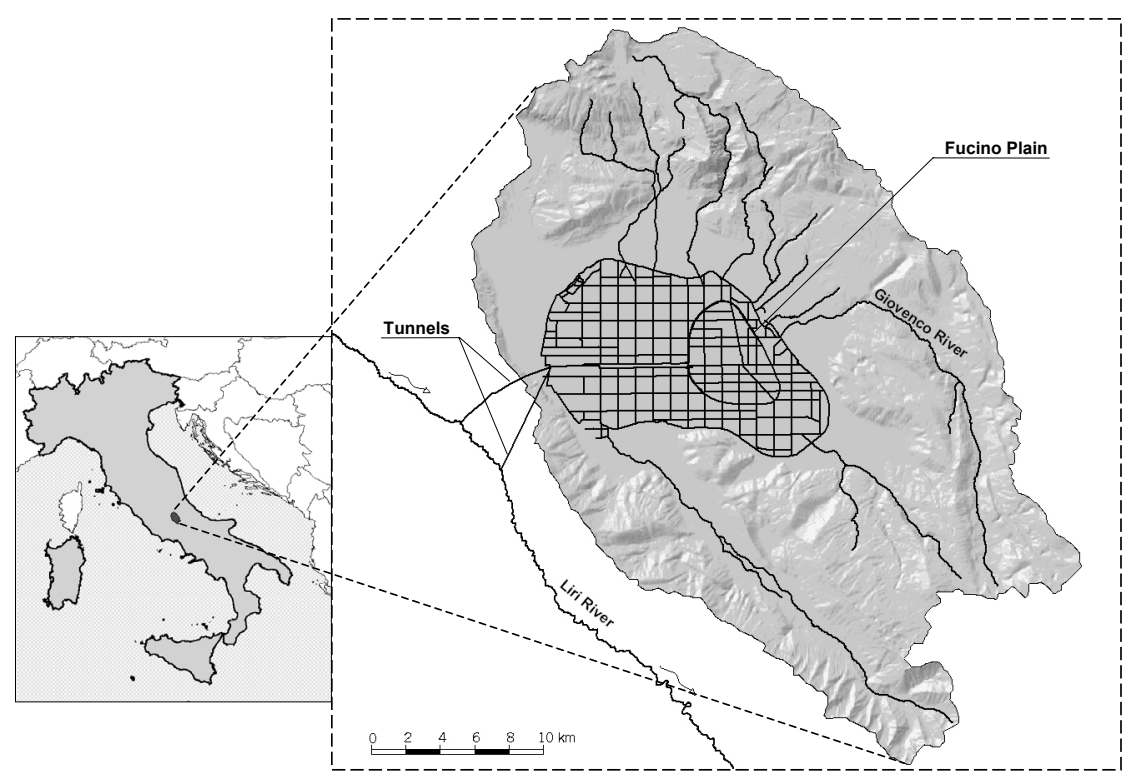

Figure 1: $\quad$ Location of the study area.

The fractured and karstified hills around the Plain are drained at their boundaries by high-discharge springs, which ensure steady discharges even during the dry season (Boni et al [5]; Burri and Petitta [6]). The climate of the area is characterised by an average yearly rainfall of $883 \mathrm{~mm}$, evapotranspiration of $609 \mathrm{~mm}$ and an average water surplus (in the Plain) equal to $220 \mathrm{~mm} /$ year. Water surpluses only occur in the November-March period. From April through October, the low amount of rainfall is not able to satisfy crop water demands and thus large amounts of water are used to irrigate farm crops.

In the past, farmers grew three main crops (wheat, potatoes and sugar beet) on the basis of a three-year rotation. These crops required minimal amount of water and the demand was satisfied by the natural flows in the canals. In the last decade, however, farmers have gradually switched to vegetable crops, such as carrots, salads, Belgian endive, fennel and celery. Vegetable crops are field grown, thanks to favourable circumstances, including the option of repeating two to three growing cycles on the same field. To be able to satisfy this large water requirement several well fields (with a total capacity of $2.6 \mathrm{~m}^{3} / \mathrm{s}$ ) have been drilled in the limestone aquifers surrounding the Plain. The water taken from the wells is discharged into the canal network, where is exploited by individual using mobile pumps via tractor 'power take offs' (PTOs) (Figure 2).

\section{Methodology for problem assessment}

To analyse the main problems of the study area and to assess the benefits of the identified measures two models were implemented: a monthly water balance 


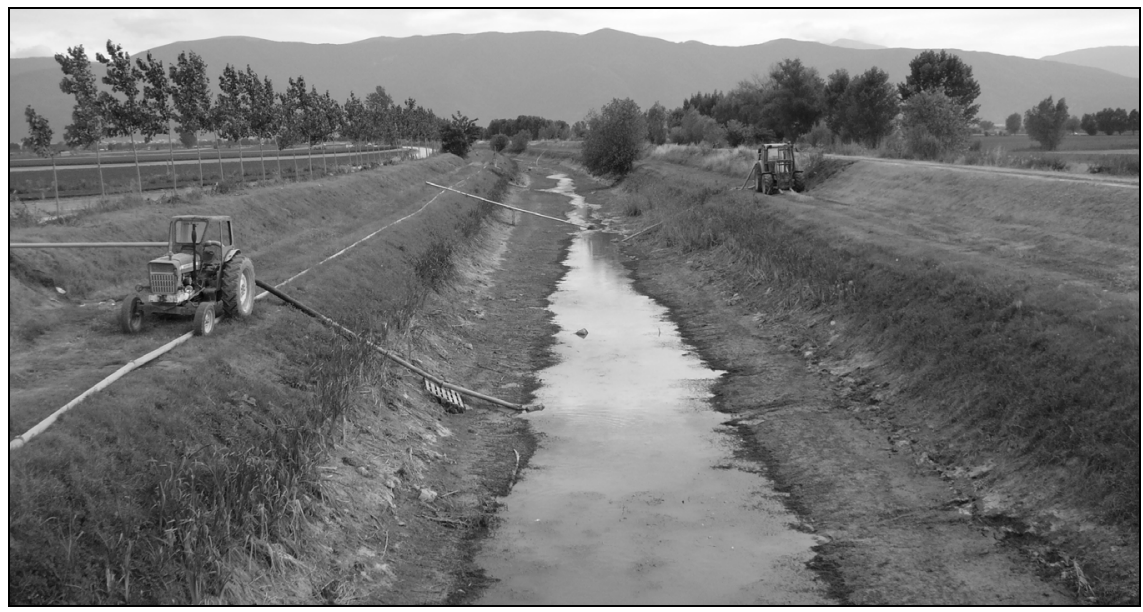

Figure 2: $\quad$ Picture that shows how the farmers use tractors to pump the small amount of water available in the canals network (summer 2007).

model for the whole catchment and a hydraulic model of the Plain channel network.

The water balance model implemented was RIBASIM (RIver BAsin SIMulation) developed by WL|Delft Hydraulics. RIBASIM simulates the behaviour of river basins under various hydrological conditions, representing through nodes and links hydrological water inputs (surface and underground), natural and artificial waterways and the water users in the basin. The implementation of the model enabled the evaluation of the quantity and flow composition of water available for the user in the basin under different hydrological condition and operational scenarios.

Considerable work was completed to develop hydrological scenarios (monthly series of surface runoff and spring flows) used as inputs in RIBASIM. This included implementing a rainfall-runoff model based on the model developed by Ibrahim and Cordery [7]. The area was subdivided in 21 subcatchment and 20 acquifers: the intersection of those identified 72 calculation elements with unique surface and underground characteristics. Each of these elements was schematised by means of two storage components: a soil storage, which represents the unsaturated zone and plays an important part in determining runoff and the amount of actual evapotranspiration, and groundwater storage, which represents saturated zones and determinates the baseflow. Input to the model consists of monthly rainfall and temperatures and soil parameters (such as soil moisture storage at wilting point and field capacity) for each calculation element. The model was successfully calibrated and validated in different locations using measured data series of rainfall, temperature and discharges from 1921 to 2002.

The hydrological model was used to develop two runoff scenarios: average and 1 in 10 year drought. These runoff scenarios were used in RIBASIM as input together with data and rules typical of the different water users (civil, industrial, 
hydropower, agriculture), and the characteristic of the main structures in the basin (wells, rivers, pipelines, sewage treatment plants, ...). A total number of 552 nodes and 679 links have been used to schematise the whole study area.

The RIBASIM model results were judged to be sufficient to identify problems and evaluate solutions for the several users in the basin except for the irrigation users in the Plain: the complexity of the hydraulic behaviour of the canal network used by farmers for irrigation meant that this required the implementation of a more detailed hydraulic model and InfoWorks was chosen for this purpose.

InfoWorks CS (Wallingford Software) allows water utilities to complete hydrological and hydraulic modelling of the complete urban and non-urban water cycle. The applications include flood risk management, pollution prediction and the modelling of water quality and sediment transport throughout networks. As well as supporting network modelling, this software is sufficiently flexible to model subcatchment abstractions and infiltration characteristics.

The Fucino Plain network $(340 \mathrm{~km})$ was implemented in InfoWorks using a 'nodes' and 'links' hydraulic representation. Moreover, to obtain an accurate model of the real situation, all gates, siphons, weirs and pumps present in the Plain were included in the model. The results obtained with RIBASIM were used as boundary conditions in the hydraulic model giving the quantity and the quality of water inflow (springs, wells, rivers, urban discharges). The water demand, drawn by the farmers, was implemented using additional orifices to represent specific outflows. InfoWorks CS model has permit to obtain accurate results considering quantity and quality balance and network propagation for the average condition of each month for average and 1 in 10 year drought.

\section{Problem assessment}

The current and future state analysis, with the use of the models described above, has defined the main irrigation and environmental problems. The major criticalities in the irrigation sector are related to the current system organization. A large amount of irrigated surfaces are not provided with a distribution system and irrigation is achieved by direct abstraction from the channels. In summary the problems are:

- water deficits for irrigation;

- poor management of the irrigation system;

- high-level of energy consumption;

- poor quality of water used for irrigation;

- use of potable quality groundwater.

In particular there are many zones in the Plain with a water deficit during summer periods when the water demand from crops is at its highest. This supplydemand deficit is related to:

- insufficient water availability for the basin as a whole and

- non-uniform distribution of water resources within the Plain.

The unsatisfied water demand is equal to $3300000 \mathrm{~m}^{3}$ for the 'average year' and $12400000 \mathrm{~m}^{3}$ for the 'critical year' (one in ten year return period). 
With regard to the irrigation system, there is an absence of coordination and planning of water use. Moreover, there is no formal irrigational scheduling to satisfy the crop life cycle. Irrigation practices are generally reactive and focused on providing water to satisfy periods of crop stress. Another important problem is related to the use and maintenance of the gates controlling the hydraulic profile in the channels with the intent to permit the water withdrawal by farmers. Detailed management across the whole area is difficult to achieve and is exacerbated by farm fragmentation (a typical irrigation plot is equal to $1.5 \mathrm{ha}$ ), which has led to the growth of low efficiency irrigation technologies.

Current irrigation operations entail a high-level of energy consumption due to well withdrawals to fill the channels and the use of tractor motor pumps (very low efficiency) to abstract water from the canals. The average water supplied yearly by underground aquifers is equal to $11300000 \mathrm{~m}^{3}$ that entails an energy consumption of $2300 \mathrm{MWh}$. Abstraction from the channels is $30720000 \mathrm{~m}^{3}$ per year with a gas oil consumption of 3 millions of litres.

The modelling results, in agreement with the analysis lead by Local Authority, show that the water quality present in the Fucino Plain channels is, in general, not appropriate for irrigation according to the present legislature. In particular in the main channels, for the medium year, Escherichia Coli is present at with counts of 100 per $100 \mathrm{ml}$ of water $(\mathrm{UFC} / 100 \mathrm{ml})$ and of $\mathrm{BOD}_{5}$ concentration is approximately $20\left(\mathrm{mg} \mathrm{O}_{2} / \mathrm{l}\right)$. The poor water quality affects product quality and therefore the commercial value of the crops grown.

The use of water resources from underground aquifers for irrigation is not sustainable and these water resources should be prioritised for human use and be preserved for future generations.

\section{Proposed measures for sustainable irrigation}

The methodology used to define the interventions was based on the study of the 'critical year' ( 1 in 10 dry year) for the baseline and future scenarios, the analysis of the Local Authority proposals and the identification and description of new interventions.

To choose the best solutions, in terms of economic benefit, appropriate location and environmental functions, a cost-benefit analysis was implemented. As part of this process interventions were refined to provide greater benefits, for example by reducing their energy use. The last step of the method is an interactive procedure to compare the various solutions.

The economic evaluation of the various cash flows permits a cost-benefit analysis that considers all aspects of a proposed solution. The evaluation methods used in this study consider also the actualization of the investments values - the Net Present Value (NPV) and the Investment Return Period, both considering a $5 \%$ of discount rate.

The study of 'current state' problems clearly shows that the structural solutions must consider the storage of surface water during winter and its use for irrigation, the distribution of water with a pressurised network and the adoption of more efficient irrigation techniques. 
The hydrological analysis demonstrated that the Giovenco River provided the only feasible option for a water intake. The study considered a reservoir design based on the maximum water volume that could be abstracted during a 'scarce year' ( 1 in 10 dry year).

The first step was to identify ten possible combinations of storage and transfer according to the hydrologic and hydrogeology characteristics of the basin, different abstraction rates and storage locations. The cost-benefit analysis approach was used to define the best solution. Taking into account this storage and conveyance solution two interventions for water distribution - rain-gun or drip - were considered. These hypotheses have been compared, with a costbenefit analysis, with two other interventions proposed by the local Authorities.

At the end of the process, the optimal solution identified was the "Project for the construction of a Giovenco river intake near Pescina, of an artificial lake near Arciprete and of a storage basin in the Tristeri valley - Drip irrigation network", coded IR54-P2 in the study (Figure 3). This project aims to realize an intake in the Giovenco river up to Pescina (East part of the basin) at $740 \mathrm{~m}$ above the sea level, a transfer pipe of $1200 \mathrm{~mm}$ of diameter and $5300 \mathrm{~m}$ long from the intake to the irrigation network in the Plain. The project also includes an artificial lake of $500000 \mathrm{~m}^{3}$ near Arciprete (in the south respect the Plain) at 710 $\mathrm{m}$ a.s.l. This elevation was indicated by the model as the optimal to have the right pressure for drip irrigation in every point of the system.

The irrigation network could transport an average annual flow of $1.06 \mathrm{~m}^{3} / \mathrm{s}$ from the intake in Giovenco river to the Arciprete Lake. In the Tristeri valley, which is a natural karstic depression up to the artificial lake (South part of the Basin), a reservoir of $9260000 \mathrm{~m}^{3}$ (maximum amount of water that can be withdraw and stored during the winter period of a scarce water year) will be realized, with a small dam (11.5 $\mathrm{m}$ high) and grouting to waterproof the base

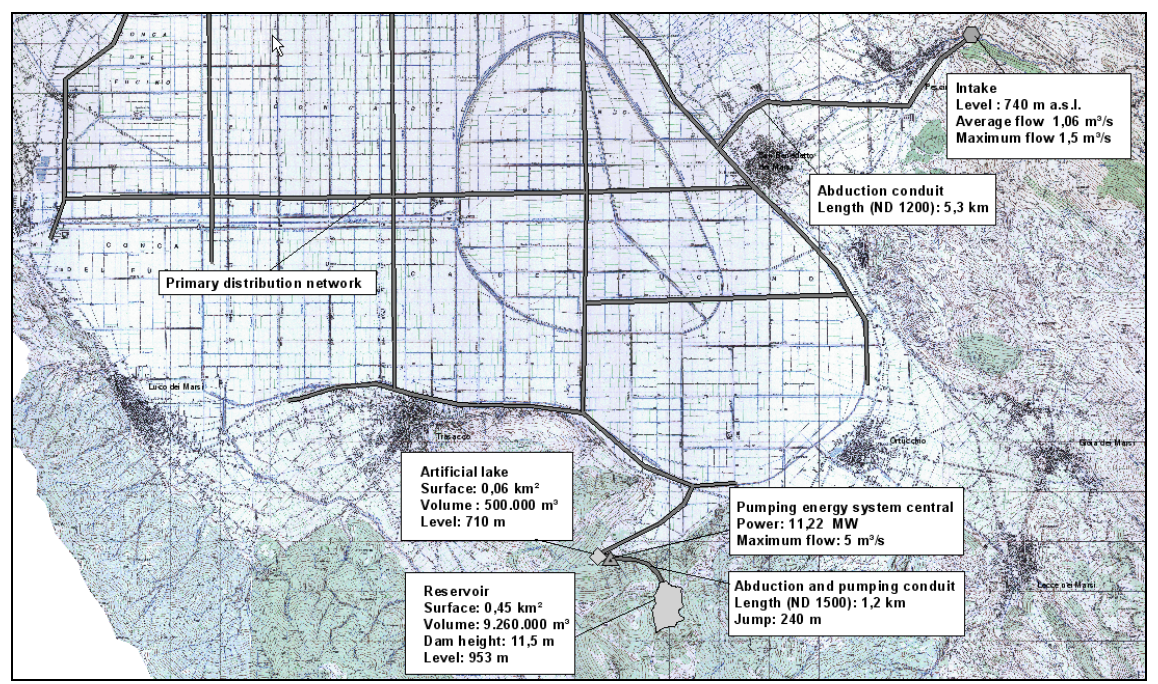

Figure 3: $\quad$ Schematisation of the solution IR54-P2. 
of the reservoir. A $1200 \mathrm{~m}$ pipe with $1500 \mathrm{~mm}$ of diameter can connect the reservoir with the lake. The head between the two lakes (more than $200 \mathrm{~m}$ ) is utilized to produce electricity with a turbine during the high energy price hours. The water is pumping up during the low price energy hours.

The project also includes a pressurised distribution network in the Plain, completely a small network which is already in place. The network can reduce the water deficit in the all Plain, level the water availability for every farmer, permit good control and improve the water quality used for irrigation as well as decrease energy consumption.

In the cost-benefit analysis the environmental and social benefits analysis have not been monetized. The economics benefits that have been taken into account for the evaluation could be absolute or relative compared with the present state. An absolute benefit is the use of hydro-power that includes selling excess hydro-energy, providing energy for the pumping system and the benefit of a Renewable Energy Certificate. Relative benefits are:

- a reduction in the costs of water pumping from underground aquifers;

- a reduction or elimination of water pumping from the channels to the fields;

- a decrease in water deficits that increases crop yield;

- improvements in product quality due to use of an unpolluted water use.

The chart below (Figure 4) compares the last four project solutions analysed using the NPV index, the black line is the IR54-P2 project, and the dark grey line just under the black one is the IR54-P1 project that differs from the IR54-P2 because it uses a rain-gun irrigation network. The two other projects have been proposed by the local Authorities. The IR01 considers to construct a surface water storage lake near the Plain and to distribute the water with a low pressure rain-gun irrigation network; the IR03 considers to use just the water from aquifers and to construct a high pressure rain-gun irrigation network supplied with four small daily storage units.

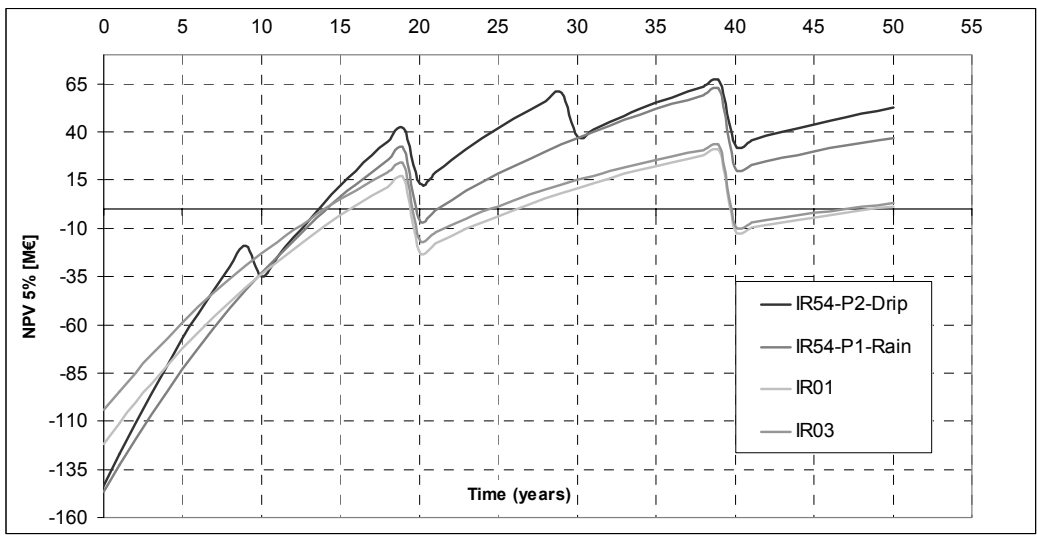

Figure 4: Net present value of the analysed measures.

The results of the economic analysis show that project IR54-P2 provides the highest cost-benefit if a long term perspective of 50 years is used. This considers 
the periodic replacement of the irrigation supply infrastructure that is more expensive for drip irrigation than for rain irrigation systems.

The benefits of the proposed measures could be summarized as follows:

- $70 \%$ reduction of precious water resources using (underground water) for the average year;

- reduction in leakage that entails a diminution of the water needed in the medium year from $46000000 \mathrm{~m}^{3}$ to $24000000 \mathrm{~m}^{3}$;

- complete satisfaction of the water demand for the medium year and reduction of the water deficit from $12000000 \mathrm{~m}^{3}$ to $2400000 \mathrm{~m}^{3}$ (-81\%) for the critical year. Note that complete water demand satisfaction entails an additional cash input of $€ 7.5$ millions per year;

- improved quality agricultural products due to the use of better quality water that causes a significant increase in commercial value (estimated to be equal to $€ 7.6$ millions per year);

- reduction of energy consumption due to the aquifer withdrawal for an amount of $€ 120000$ per year, and due to the cancellation of the motor pump withdrawal from canals that has been quantified to be equal to $€ 2.2$ millions per year;

- energy production benefit of the pumping system for on amount of 1.4 millions of $€ /$ year;

- better user coordination, management and irrigation scheduling.

\section{Conclusion}

The results obtained through a cost-benefit analysis of possible solutions to overcome irrigation water scarcity and poor quality problems in the Fucino Plain show that it is possible to find measures that are not only effective in reducing the current environmental problems of the area but are also beneficial from an economic point of view.

The proposals require active involvement and 'buy-in' from the farming community that will have to adopt new irrigation techniques. Their participation in the planning and decision-making processes is crucial so that widely acceptable solutions for irrigation and more general for river basin planning can be promoted in the catchment.

The proposed measures are based on shared knowledge, experiences and a scientific approach including the use of a validated water balance models, hydraulic modelling tools and cost-benefit analysis, which is fundamental to improve decision-making.

The potential benefits of completing this study, which combined considerations, related to public water supply, irrigation and water quality include:

- an increased public awareness of environmental problems in Fucino basin;

- more transparent decision making by considering a wide range of interventions and cost-benefit methods that included environmental considerations; 
- less misunderstanding about the costs and benefits associated with particular environmental problems and possible solutions;

- public acceptance, commitment and support with regard to decision taking processes.

\section{Acknowledgements}

This paper presents part of the activities promoted by the Liri-Garigliano and Volturno River Basin Authority and the Abruzzo Region awarded to BETA Studio srl and HR Wallingford Ltd: "Design of a program for the protection, use and management of the surface and ground water resources of the Fucino plain (Abruzzo region), combining structural and non-structural measures" in 2007. The authors gratefully acknowledge Dr. Vera Corbelli (Technical Director and General Secretary of the Liri-Garigliano and Volturno River Basin Authority) and the staff involved in the study that provided us with useful and helpful assistance.

\section{References}

[1] Burri, E. \& Petitta, M., Agricultural changes affecting water availability: from abundance to scarcity (Fucino Plain, Central Italy). Irrigation and Drainage, 53, pp. 287-299, 2004.

[2] BETA Studio srl \& HR Wallingford, Design of a program for the protection, use and management of the surface and ground water resources of the Fucino plain (Abruzzo region), combining structural and nonstructural measures, Liri-Garigliano and Volturno River Basin Authority, Abruzzo Region, 2007.

[3] Brisse, A., \& De Rotrou, L., Dessechément du Lac Fucino executé par S.E. le Prince Alexandre Torlonia. Precis historiques, Impremerie de la Propagande, Roma, 1876.

[4] Ciotoli, G., Guerra, M., Lombardi, S. \& Vittori, E., Soil gas survey for tracing seismogenic faults: a case study in the Fucino basin, Central Italy. Journal of Geophysical Research, 103, pp. 23781-23794, 1998.

[5] Boni, C., Bono, P. \& Capelli, G., Schema Idrogeologico dell'Italia centrale. Memorie Società Geologica Italiana, 36, pp. 991-1012, 1986.

[6] Burri, E. \& Petitta, M., Farming and water management in the Fucino Plain in the last century. Proc. of the XVII Int. Congr. ICID, Granada, 1D, pp. 257-268, 1999.

[7] Ibrahim, A.B. \& Cordery, I., Estimation of recharge and runoff volumes from ungauged catchments in eastern Australia. Hydrological Sciences Journal, 40(4), pp. 499-515, 1995. 